\title{
Mark Twain Viajante: Um olhar nada inocente
}

José Flávio da Paz ${ }^{1}$

DOCA, Heloisa Helou. Mark Twain viajante: um olhar nada inocente. - São Paulo: Arte \& Ciência, 2012. 291 p.

A obra Mark Twain viajante: um olhar nada inocente foi publicada em 2012 unindo elementos textuais do doutorado da escritora, ocasião que se envolveu profundamente com a obra e a vida de Mark Twain, tornando-se conhecedora e admiradora dos seus relatos das viagens realizadas por terras norte-americanas.

O livro compõe 291 páginas divididas em introdução e mais quatro capítulos, com aproximadamente sessenta páginas cada. O prefácio coube a Thomas Bonnici, doutor em Teoria da Literatura pela Universidade Estadual Paulista Júlio de Mesquita FilhoUNESP, atualmente docente da Universidade Estadual de Maringá-UEM.

As considerações finais são feitas em apenas seis páginas. Todavia, a extensa bibliografia e os anexos constituídos de documentação comprobatória dão à obra um grande valor. Certamente, esta talvez seja a real intenção da escritora, de modo que atribuísse à sua obra maior relevância e veracidade dos fatos apresentados ao longo da sua produção, além de apresentar elementos concretos que se aproximem o cotidiano do leitor.

Um dos grandes feitos da autora tem início na capa da obra que ilustra muito dos seus anseios e expectativas a discorrer em seu livro. Apresenta-se Mark Twain com uma mala debaixo do braço e guarda-chuva na mão direita, sobre uma águia, símbolo do Imperialismo, com rédeas, guiadas com a mão esquerda e esporas caracterizando a sede voraz dos Estados Unidos em explorar e dominar povos e terras longínquas. Ele sobrevoa o mapa-múndi, com ênfase nas imagens da Torre Eiffel, dos templos, igrejas, centros, sinagogas e mesquitas do Oriente e da Esfinge de Gizé, possíveis locais inspiradores da cultura americana, mas invejado por seus políticos, graças às riquezas materiais e imateriais apresentadas por aqueles grupos sociais. Nas garras da águia são carregadas bandeiras, além da dos Estados Unidos, outras de oito nações: Filipinas, Cuba, Guame,

\footnotetext{
${ }^{1}$ Mestre em Letras, com área de concentração em Literatura Comparada das Literaturas de Língua Portuguesa-UNIMAR; Doutorando em Educação-WIU/USA.
}

Revista Crioula USP, $\mathrm{n}^{\mathrm{o}}$ 17, junho de 2016 
Marrocos, Síria, Açores, Austrália e Panamá, sob o possível domínio ou exploração do modelo imperialista adotado pelos Estados Unidos. Talvez, a autora apresente estes grandes monumentos e algumas maravilhas mundiais como forma de criticar tais posturas americanas, mas também um modo de expressar preocupações de Mark Twain e os seus sentimentos de amor, respeito, cooperação, companheirismo e outros que sentiu pelos povos dos Estados Unidos, em especial, as minorias, como citado durante todo o livro, mais ainda, as viagens e experiências mundiais.

Ainda o apresenta fumando charuto. Mark Twain tinha como vício fumar cigarros baratos, para ele qualquer charuto era charuto. Daí, seu charuto favorito era qualquer um, desde que não fosse de Havana, Cuba. Isto porque os Estados Unidos tinha aquele País como arqui-inimigo por não se sujeitar às normas ditatoriais políticas da época.

Ainda na capa, existe a representação do Cometa Halley, isto porque Mark Twain nasceu duas semanas depois da passagem do cometa em 1885. Segundo a autora, ele disse que veio com o cometa Halley em 1835 e que iria com ele na sua próxima passagem - em 1910, fato que prenunciava sua morte. Mark Twain morreu aos 76 anos de idade, em 1910 e no dia seguinte à altura em que o cometa esteve mais próximo da Terra.

Em Mark Twain viajante: um olhar nada inocente, a autora emprega a primeira pessoa para construir um texto e, sendo uma obra científico-científica apresenta uma linguagem dialógica clara e objetiva, de modo que o leitor se sinta próximo aos fatos e mesmo da autora, favorecendo uma experiência virtual dos diversos deslocamentos que a obra propicia, uma vez que se trata de uma produção que, também, relata as inúmeras viagens realizadas pelo protagonista dos textos, além da sua sensibilidade para com as causas da população negra explorada para edificação e solidificação do Estado Americano, antes da Guerra Civil e em períodos posteriores à Emancipação, bem como a ignorância das mulheres e homens brancos e o que diz em cláusulas Constitucionais e das leis trabalhistas da época para esta questão.

Através da personagem protagonista - Mark Twain, a autora faz críticas ao processo de americanização que aniquilou a identidade, a cultura e a memória dos primeiros habitantes das terras da América do Norte; denuncia as estratificações e opressões étnico-raciais e a hipocrisia utilizada para constituir aquele modelo socioeconômico, educacional e cultural estadunidense. Isto porque em documentos anexos ao livro, o próprio Mark Twain assim se apresenta, ou seja, ele optou por se posicionar contrário à política anti-imperialista adotada pelos Estados Unidos. 
$\mathrm{Na}$ introdução, a autora faz um trajeto histórico oportuno para contextualização da obra Mark Twain viajante: um olhar nada inocente. Versa sobre o processo de expansão colonial adotado no início do século XIX, cujo lema era baseado na Doutrina Monroe, "A América para os Americanos", anunciada pelo presidente estadunidense James Monroe (1817-1825) em sua mensagem ao Congresso em 2 de dezembro de 1823.

Apresenta-nos a Guerra Civil Americana, uma guerra civil que ocorreu nos Estados Unidos da América entre 1861 e 1865. Ressalta-se que esta foi a guerra que causou mais mortes de americanos, cujo desfecho, e mesmo os próprios nomes da guerra, são motivos de controvérsia e debate até os dias atuais, embora exista grande interesse da autora, através de documentos apresentados nos anexos, de enfatizar os interesses políticos da época e denunciá-los através do seu protagonista, tornando-o cético e ambivalente diante das tragédias vivenciadas pelos americanos, negando os princípios igualitários, enquanto cidadão e ser humano.

As bases teóricas, sustentadas em antropólogos, historiadores, socialistas, filósofos e outros pesquisadores são apresentadas através de pensadores como Eliot, Raymond Williams, Edward Said, Jonathan Arac, Todorov, Bakhtin, Maria Silvia Betti, Harriet Ritvo, Charles Bernheimer, Matthew Arnold, Jim Zwick e muitos outros, cujas referências são salutares à riqueza da obra Mark Twain viajante: um olhar nada inocente.

A obra apresenta notas de rodapé com traduções em língua portuguesa das expressões em inglês apresentadas durante a obra, o que favorece a compreensão daqueles leigos nesta língua. Isto demonstra a preocupação da autora por uma interação clara e precisa junto a todo e qualquer leitor que, por ventura, viesse sentir dificuldade na leitura e interpretação dessas falas, visto que o teor do livro, em parte, diz respeito à história e à cultura dos povos estadunidenses.

No primeiro capítulo, há um enorme interesse em definir os modelos culturais e folclóricos existentes antes e durante a chegada dos exploradores. Tais como a oralidade e sua importância para a manutenção da identidade dos primeiros habitantes, bem como a alteridade imbricada nas entrelinhas das expressões da autora ou do seu personagem, em especial quando envolvem questões globais, democráticas, (des)colonização do contexto pós-colonial.

A autora apresenta quatro subtópicos, cujos objetivos são conceituar Literatura Comparada, multiculturalidade, cultura, sociedade, a alteridade como a metamorfose do olhar do outro e as construções culturais através das viagens. Inclusive, com forte ênfase 
na concepção do olhar, do seu olhar sobre algo e o olhar do outro sobre nós ou qualquer coisa à nossa volta em novas experiências literárias e culturais.

A concepçção sobre Literatura Comparada é apresentada, segundo Matthew Arnold, cujas ideia, conforme a autora, citando Arnold apud Williams (1992, p. 27): "envolve o estudo de textos interculturais através do tempo e do espaço". (p. 21). A ideia é reforçada através dos conceitos de Goethe apud Cevasco (2003, p. 38), entre outros, chegando às origens daquele que, na prática iniciou o comparatismo literário: Dante Alighieri, com a obra De vulgari eloquentia, sendo este o marco da Literatura Comparada.

Cita ainda, os romanos, episódios da Idade Média e do Iluminismo, com atenção a países europeus como sendo o berço da sistematização da Literatura Comparada e, em especial, ao alemão Goethe por cunhar, inicialmente, o termo Literatura Mundial. Todavia, a expressão Literatura Comparada, finalmente, tem seus princípios e pressupostos afirmados a partir do inglês Hutcheson Macaulay Posnet, em 1886, na obra Comparative Literature.

Seguindo o raciocínio lógico da autora e a apresentação dos movimentos contrários aos moldes da Literatura Comparada, surgem os Estudos Culturais garantindo as minorias: negros, homossexuais, mulheres e pessoas de classe social desassistida, como sendo provedores de ideias que sustentam o sistema, através das oralidades e dos seus produtos culturais. Há, portanto, severas críticas à alta literatura, ou às literaturas canônicas que ignoraram a cultura local e implantam e implementam uma cultura literária baseada no olhar europeu, bem como seus escritos que mostram ao mundo apenas as maravilhas locais sob o olhar do explorador.

No posicionamento apresentado pela autora, ao citar a Associação Americana de Literatura Compara - ACLA, e esta enquanto organizadora de relatórios sobre a Literatura Comparada, como também os estudiosos americanos, ambos sustentam os estudos dessa disciplina em um tripé de saberes: globalização, democratização e descolonização. Baseados nestas premissas, os conteúdos seriam altamente proveitosos não só no âmbito da literatura, mas nas possibilidades dialógicas entre as culturas apresentadas nessas produções literárias, em especial quando valorizadas as práticas narrativas das diversas sociedades subjugadas como secundárias ou insignificantes.

Daí, talvez, o interesse da autora em provocar o deslocamento do leitor mundo afora, ou seja, a promoção das viagens como forma de crescimento pessoal e profissional, todavia, a essência cultural do indivíduo deve ser preservada por se tratar de um sujeito único neste mundo, mas consciente de que esta iniciativa o conduzirá a um crescimento 
cultural, de aperfeiçoamento humano e das suas práticas funcionais. Isso é feito através da adoção de novos modos de vida, hábitos e costumes de outras culturas em favor da sua, reconhecendo que a sua cultura deve ser venerada, mas a do outro também tem seu valor e significativa importância para a história mundial das civilizações.

A história da cultura e a origem da expressão são questões dirimidas no livro, considerando os aspectos inerentes à cultura e à civilização, como ideia do civilizado em oposição ao bárbaro. Os conceitos são apresentados no modo reflexivo da época e na contemporaneidade. Isto porque continuamos a nos apresentar de tal forma - bom-mau, branco-negro, santo-pecador e assim por diante. Os processos semióticos e sociais nos fazem interpretar o mundo nos seus extremos, considerando que viemos deste modelo. Todavia, o respeito à cultura do outro também é a máxima da obra Mark Twain viajante: um olhar nada inocente, levando o leitor reconhecer que as culturas e as sociedades americanas estão sustentadas sob a cultura europeia.

Os argumentos sobre alteridade estão fundamentados em Foucault (2004, p. 4); Novaes (1995, p. 10); Bornheim (1995, p. 18 e 25) e outros pensadores, filósofos, linguístas e poetas como Platão, Plutarco, Lucrécio, Epicuro, Marx, Merleau-Ponty, Bosi, Todorov, Hulme, Sharkey, Donne, Ribeiro, Bakhtin entre outros, inclusive cantores como Caetano Veloso, quando desenvolve intertextualidade entre o texto "Elegia" deste e o texto "Elegia: indo para o leito" do poeta inglês John Donne.

Dados os pensadores, a autora distingue expressões como consciência intelectual de consciência sensível. Conceitua sentido, conhecimento, espaço vazio em Epicuro e ideia de vazio em Foucault. Trata de aspectos como fenomenologia; o olhar além do simples ver as coisas e as situações do mundo contemporâneo. Conceitua também o olhar vigilante dos leitores sobre obras literárias e/ou produções artísticas, inclusive nas suas viagens para descobertas de novos mundos e culturas.

Encerrando estes subtópicos, a escritora versará sobre aspectos antropológicos, canibalismo, cultura dominante, a função das narrativas de viagens e a interpretação do olhar explorador dominante e não dominante, a cultura observada e o observador, bem como suas expressões reforçadas de aceitação ou rejeição da cultura alheia. A autora ressalta a importância do negro na história cultural dos Estados Unidos, segundo a ótica de seu protagonista. Traça uma discussão entre Mark Twain com Fenimore, Cooper, Poe, Melville, Eliot e Pound sobre os arquétipos culturais americanos e europeus difundidos por estes escritores, na tentativa de desmistificá-las e dá-lhes um sentido real da cultura instalada na América do Norte. 
No segundo capítulo, também distribuído em quatro subtópicos, a autora relata os aspectos históricos da vida de Mark Twain que envolve períodos não cronológicos, passando pelo seu nascimento e trazendo à tona a reflexão sobre a passagem do cometa Halley sobre o planeta Terra, seu rastro que vai além do ícone até o surgimento das concepções anti-imperialistas adotadas por ele em suas viagens.

A autora compara a luz do cometa à luz terrena traçada por Mark Twain durante sua estada entre nós, que contemplou e continua a contemplar a todos, seja da área literária, filosófica, história, sociológica ou quaisquer outras com seus saberes, conhecimentos e informações anti-imperialistas, embora a política ditatorial insista em negar sua contribuição nos campos dos estudos literários e historiográficos, dado seu desconhecimento ou mesmo "censura", como destaca.

Resgatando os estudos da sua dissertação, a autora reafirma que Mark Twain era um homem de múltiplos talentos, foi humorista, ficcionista, jornalista, conferencista e crítico das mudanças sociais provocadas pelos Estados Unidos, em especial, no período da Guerra da Secessão no início do século XIX. Toda sua crítica estava impregnada de concepções anti-imperialistas e expansionistas imperialistas norte-americanas. Isto levou-o a integrar a Liga Anti-Imperialista Norte-Americana, instigando a sua produção literária e demais talentos nas causas anti-imperialistas.

A escritora faz uma biografia do autor e apresenta seu nome verdadeiro e as suas origens. Samuel Langhorne Clemens, assim se chamava Mark Twain, nascido na Flórida no estado de Missouri, de família oriunda do estado de Tennessee, vitimados pela opressão, domínio e as injustiças sociais da época. De certo, suas lembranças infantis estão refletidas nas suas obras e nas mentes dos seus leitores. Continua sua trajetória vital nas páginas seguintes da obra, aos 10, 12 anos de idade e nas experiências dos anos de 1861, começo da Guerra Civil e sua mudança para o estado de Nevada.

Em 1864, segue para São Francisco onde irá trabalhar como repórter de Golden Era. Através da sua atuação funcional é designado para Califórnia, Ilhas Sandwich e depois para a Europa e para o Oriente. Daí em diante, Mark Twain ainda como correspondente do Golden Era empreita sua jornada como conferencista e, dado o seu sucesso, surgem 16 outras exposições por toda a região.

Em 1866, em Nova Iorque, publica seu primeiro livro. Nesse instante, Mark Twain já não era mais apenas correspondente do Golden Era, mas também do Tribune, da Califórnia e Nova Iorque respectivamente. 
Em 1867, retorna à Europa e ao Oriente. Em 1870, casa-se com Olívia Langdon e com a ajuda do sogro compra parte de um jornal em Buffalo, já em 1871, ocasião em que se estabelece em Hartford, em meio à elite da Nova Inglaterra. Nasce também sua primeira filha, Suzan. Nesta ocasião, seu trabalho já tinha reconhecimento nacional, desfrutava de uma estabilidade financeira e vivia da profissão de escritor.

É apresentado pela autora como sujeito empreendedor e as viagens que se seguiram vida afora estavam ligadas diretamente à sua produção literária. Todavia, dois fatores narrados pela autora fazem com que ele se mude para a Europa - as mortes da sua mãe e da sua sogra, em 1890, e o cansaço das viagens para apresentação das suas conferências.

A autora destaca os romances e atribui uma pequena síntese aos títulos de Mark Twain considerados clássicos da literatura norte-americana: As aventuras de Tom Sawyer (1876); O Príncipe e o Plebeu (1881); As Aventuras de Huckleberry Finn (1884) e Um Ianque na Corte do Rei Arthur (1889).

Finaliza o capítulo destinado ao estudo da águia, símbolo nacional norteamericano sob a ótica de Mark Twain, que a vê como uma ave de rapina, usurpadora de povos e terras minoritárias e escravizadora.

O terceiro capítulo relata as repercussões do pensamento de Mark Twain em Portugal e no Brasil. Novamente a autora distribui seus argumentos em quatro subtópicos e tratará de concepções a respeito do colonizado e dos colonizadores; das composições de Mark Twain, dos ilustradores, das ilustrações e da recepção dos feitos twainanos e a dessacralização da tradição dos mitos e das culturas do Velho Mundo.

A autora introduz o capítulo com relatos históricos datados entre os anos 1400 e 1500 e suas colisões de mundos, culturas, línguas e literaturas. Reapresenta-nos o Novo Mundo, seu ideário e sustenta suas afirmativas em teóricos como Mauk (1995, p. 3); Lemay (1988, p.38); Arnold (1993, p. 45); Said (2003, p. 115); Bhabha (1995, p. 19); Beni (2000, p. 87), entre outros.

Seu interesse é nos transportar a estes períodos históricos e reconhecer a constituição humana de Mark Twain e sua contribuição para a interpretação do novo momento que se construía, a visão de mundo que se devia alargar sobre os efeitos sociais e humanitários.

Deleita-nos com Mark Twain iniciante em suas narrativas, cujos propósitos talvez nem fossem chegar a tais projeções, mas o fazia sem se preocupar com os critérios dos 
esquemas convencionais das narrativas. Simplesmente as fazia. Portanto, os diferentes tipos de escrita, misturam-se para compor a gênese social de Mark Twain (p. 126).

A autora repete o estilo de ilustração adotado nas obras twainianas, uma vez que criam um apelo importante nas vendas, considerando que suas obras eram comercializadas sob assinaturas, logo as vendas fora desse modelo requeriam maiores e melhores detalhes ilustrativos, pois estas "davam sentido à história, fazendo valer a premissa: 'uma imagem vale mais que mil palavras' e delineavam o estilo que o consumidor em potencial iria ler" (p. 131).

No último capítulo são analisadas as viagens de Mark Twain ao Gilbraltar, Tânger, França, Itália e ao Oriente, dando um caráter macropolítico no âmbito dos Estudos Culturais e da Literatura Comparada. Diferentemente dos três capítulos anteriores, a autora constitui cinco subtópicos para dissertar sobre as respectivas viagens.

Apenas neste capítulo, após profundo embasamento teórico disseminado e apreendido pelo leitor, serão apresentadas e discutidas as grandes viagens de Mark Twain. Feito intencional da autora que não deixa de nos contextualizar histórica e geograficamente.

Apresenta-nos um Mark Twain crítico também do governo português que atribui ao governo militar a supremacia sobre o governo civil. Apresenta-nos ainda, um Mark Twain cômico baseado nas ironias das suas publicações, graças às suas viagens e, embora usando de tom depreciativo, é contra o jogo dos portugueses.

Em Açores, Mark Twain visita igrejas católicas e, ao se referir aos jesuítas, os vê como impostores. Em Gibraltar relembra a história da rainha da Espanha, cujo fim é relacionar a generosidade da coroa às armas e canhões que se misturam ao cenário do estreito, construindo humor sobre tal feito utilizando a expressão "isto é Régio", os navios aportam em Tânger - Marrocos para exprimir o reconhecimento de que aqueles povos constituem mais seres explorados pelo imperialismo.

Os feitos são repetidos quando chega à França e à Itália. O esnobismo é uma frequente e as críticas contínuas, em especial quanto ao trato de transportes públicos. Neste momento percebe-se certo orgulho "nacionalista" do protagonista oriundo de uma América "notável” (p. 188).

Nas considerações finais a autora conclui que os relatos de Mark Twain serviram para construir um novo olhar sobre o mundo e de suas ideias houve o surgimento de uma disciplina, cuja sustentação está nas bases culturais de cada povo ou nação. Conclui 
também que todos os autores citados na sua obra reafirmam a grande colaboração de Mark Twain aos estudos comparativos literários.

Consta dos anexos da obra o Relatório Bernheimer: a Literatura Comparada na virada do século, o texto "Só um negro", informações históricas e outros quatro textos, além de registros informacionais e fotocopiados dos seus originais que sustentam as teses apresentadas pela autora.

O livro Mark Twain viajante: um olhar nada inocente é altamente indicado aos profissionais das mais diversas áreas do conhecimento humano e social, pois embora seja de caráter técnico-científico, apresenta uma linguagem clara e objetiva, atendendo aos mais diversos leitores formais, ou seja, aqueles que já possuem o hábito de leituras densas, pormenorizadas, e cheia de detalhes.

Daí acredita-se que qualquer indivíduo com um mínimo de leitura crítica e autônoma fará um excelente proveito dos conhecimentos históricos, sociais, geográficos, literários e outros que a autora nos induz a buscar, mesmo que seja uma leitura iniciante, ingressante nos estudos universitários.

Sua leitura traz grande contributo sócio histórico ao meio acadêmico e, em termos conceituais, à literatura, às letras e à comunicação, estando seus estudiosos favoravelmente assistidos. Certamente porque a autora, Heloisa Helou Doca possui graduação, mestrado e doutorado em letras pela Universidade Estadual Paulista UNESP. E também seja professora pesquisadora e orientadora acadêmica no Programa de Pós-graduação em Letras da Universidade de Marília - UNIMAR, além da vastíssima experiência em Literatura de Língua Inglesa, Teoria Literária, Literatura Pós-colonial, Tradução Literária e Transcodificações Mediáticas.

Possui ainda, inúmeros artigos na área de Letras e Comunicação. É autora do livro Estudos de Literatura Africana Contemporânea, juntamente com o doutor Altamir Botoso lançado pela Editora Canal 6, também em 2012.

\section{Referência Bibliográfica}

As Esfinges Egípcias. In.: http://antigoegito.org/as-esfinges-egipcias/. Acesso em 03.dez.2013.

As sete maravilhas do mundo. In.: http://minilua.com/as-sete-maravilhas-do-mundomoderno/\#reading. Acesso em 03.dez.2013.

Curiosidades sobre o cometa Halley. In.: http://curiosidadenamatematica.blogspot.com.br/2010/04/curiosidades-sobre-o-cometahalley.html. Acesso em 03.dez.2013.

DOCA, Heloisa Helou. Mark Twain viajante: um olhar nada inocente. - São Paulo: Arte \& Ciência, 2012. 
Mesquita Hasan - Oriente Médio.

http://malucoporjesus.wordpress.com/2010/03/14/a-dinamica-do-amor/mesquita-hasanoriente-medio/. Acesso em 03.dez.2013.

Torre Eiffel. In.: http://www.franca-turismo.com/eiffel.htm. Acesso em 03.dez.2013. 